\title{
Availability of legalized cannabis reduces demand for illegal cannabis among Canadian cannabis users: evidence from a behavioural economic substitution paradigm
}

\author{
Michael Amlung ${ }^{1,2,3} \cdot$ James MacKillop ${ }^{1,2,3,4}$
}

Received: 17 July 2018 / Accepted: 15 November 2018 / Published online: 6 December 2018

(C) The Canadian Public Health Association 2018

\begin{abstract}
In the context of cannabis legalization, an important question among clinicians, policymakers, and the public is whether availability of legal cannabis will significantly reduce consumption (demand) of illegal cannabis. Using paradigms from behavioural economics, we tested the prediction that legal cannabis would be an asymmetrical substitute for illegal cannabis, with legal cannabis operating as a superior commodity based on its regulated status. In a sample of 289 adult cannabis users in Ontario, we found evidence of substitutability for both legal and illegal cannabis, but significantly lower substitutability of illegal for legal cannabis, a pattern that was also present for price elasticity $(\alpha)$ and $P_{\max }$. Thus, the data indicated asymmetric substitution such that the availability of legal cannabis substantially decreased demand for illegal cannabis, but a significantly smaller effect in reverse. These results suggest that the introduction of legal cannabis into the market may disrupt and reduce illegal purchases, contributing to the reduction of the potential harms associated with the illegal market. However, in revealing price windows in which legal cannabis is preferred over the contraband alternative, these data also have significant implications for pricing policies.
\end{abstract}

\section{Résumé}

Dans le contexte de la légalisation du cannabis, l'une des grandes questions qui se posent chez les cliniciens, les responsables des politiques et dans la population est de savoir si la disponibilité du cannabis légal réduira sensiblement la consommation (la demande) du cannabis illégal. À l'aide des paradigmes de l'économie comportementale, nous avons testé la prédiction selon laquelle le cannabis légal sera un substitut asymétrique au cannabis illégal et constituera un produit supérieur en raison de son statut réglementé. Dans un échantillon de 289 consommateurs de cannabis adultes en Ontario, nous avons observé des indices de substituabilité tant pour le cannabis légal que pour le produit illégal, mais une substituabilité sensiblement moindre du produit légal par le produit illégal, tendance qui était également présente pour l'élasticité des prix $(\alpha)$ et le $P_{\max }$. Les données font donc état d'une substitution asymétrique : la disponibilité du cannabis légal réduit sensiblement la demande de cannabis illégal, mais l'effet inverse est sensiblement moindre. Ces résultats indiquent que l'introduction du cannabis légal sur le marché pourrait désorganiser et faire diminuer les achats de cannabis illégal, réduisant ainsi les méfaits possibles associés au marché illégal. En spécifiant les fenêtres de prix où le cannabis légal est préféré aux produits de contrebande, nos données ont aussi des conséquences importantes pour les politiques d'établissement des prix.

Keywords Cannabis $\cdot$ Legalization $\cdot$ Demand $\cdot$ Substitution $\cdot$ Behavioural economics

Mots-clés Cannabis $\cdot$ Légalisation $\cdot$ Demande $\cdot$ Substitution $\cdot$ Économie comportementale

Electronic supplementary material The online version of this article (https://doi.org/10.17269/s41997-018-0160-4) contains supplementary material, which is available to authorized users.

Michael Amlung

amlungm@mcmaster.ca

1 Peter Boris Centre for Addictions Research, McMaster University and St. Joseph's Healthcare Hamilton, 100 West 5th St, Hamilton, ON L8N 3K7, Canada
2 Michael G. DeGroote Centre for Medicinal Cannabis Research, McMaster University, Hamilton, ON, Canada

3 Department of Psychiatry and Behavioural Neurosciences, McMaster University, Hamilton, ON, Canada

4 Homewood Research Institute, Guelph, ON, Canada 
Cannabis is the most commonly used addictive substance in Canada after alcohol and tobacco (Canadian Centre on Substance Abuse 2017). The health implications of cannabis use include risk of cannabis use disorder, respiratory illness, exacerbation of psychiatric disorders, altered brain development, among others (Volkow et al. 2014). With recreational cannabis now legal in Canada as of October 2018, there is significant interest among clinicians, policymakers, and the public about the potential consequences of legal access (Rehm et al. 2016). A central issue raised by federal and provincial governments is whether legal cannabis will effectively displace the illegal cannabis market (also known as the "black market"). An important factor in whether legal cannabis will suppress the illegal market is price; if pricing of legal cannabis is not properly calibrated, consumers may continue to patronize illegal sources. Therefore, empirical data on the relationship between price and consumption of cannabis are critical for developing evidence-based policy. In this Commentary, we provide initial empirical evidence from a behavioural economic substitution paradigm that evaluates the extent to which legal cannabis would be expected to reduce consumption from illegal sources.

Behavioural economics provides a framework for quantifying how price of cannabis impacts preferences for legal and illicit sources. A common method of evaluating the impact of price on consumption is to examine elasticity (i.e., the proportionate change in consumption of a commodity as a function of changes in price). Demand curve analysis examines changes in consumption as a function of various influences including both price and the availability of alternatives. In research settings, demand for cannabis can be readily quantified using a validated marijuana purchase task (MPT), which assesses consumption of cannabis across a range of prices (Aston et al. 2015; Collins et al. 2014). In turn, substitutability analysis examines whether demand for a commodity goes up, down, or stays the same in the presence of an alternative option. If demand for one commodity decreases in the presence of an alternative, then the alternative is considered a substitute (Hursh 2014). Alternatively, if demand for one increases in the presence of the other, they are complementary commodities, meaning the opportunity for one enhances the value of the other, and if demand for one is not affected by the other, they are independent commodities.

The central question here is whether legal cannabis is an effective substitute for illegal cannabis, resulting in a significant reduction in demand for the illegal option. The current study used a novel behavioural economic substitution task to investigate the impact of legalized cannabis on consumption of illegal cannabis in a simulated market to model preferences when both options are available. Regulated markets are putatively preferable to contraband markets because regulatory oversight ensures quality and safety standards, and these standards were part of the rationale for Bill C-45, The Cannabis
Act. Our hypothesis was that substitutability would be present for legal vs. illegal cannabis, but it would be asymmetrical and would favour legal cannabis as a superior good based on the qualities of regulated products.

\section{Methodology}

Data were collected from November 2017 to February 2018. Although Bill C-45 was passed by the Canadian government in June 2017, recreational cannabis was still illegal at the time of data collection. A sample of 289 Canadian adult cannabis users were recruited from the Hamilton, ON community (full recruitment details in Supplemental Methods). Participants were required to be at least 18 years old and report using cannabis in the past 6 months. The sample was $40.1 \%$ female, $84.4 \%$ Caucasian, mean age of $31.7(S D=9.9)$, mean education of 15.5 years $(S D=2.5)$, and median income of $C D N \$ 79,000$. On average, participants reported using cannabis $2-4 \times /$ month, with $35 \%$ of participants using $>4 \times /$ week. The mean Cannabis Use Disorders Identification Test-Revised (CUDIT-R) score was $9.1(S D=6.4)$, and $50.2 \%$ of participants reported hazardous use (i.e., CUDIT- $R \geq 8$ ). These rates of cannabis use are generally consistent with the larger population of Ontario cannabis users (Ialomiteanu et al. 2016). Most participants (81\%) reported purchasing cannabis in the last 6 months $(M=\$ 106.56)$.

Participants completed a single online assessment including measures related to cannabis use, mental health, personality factors, demographics, and a cannabis substitution paradigm (see Supplementary Methods). All participants gave informed consent and received gift cards as incentives; the study was approved by the Hamilton Integrated Research Ethics Board.

Participants completed a modified MPT Substitution Paradigm for legal and illegal cannabis based on a validated paradigm for tobacco (Johnson et al. 2017). Two MPTs assessed hypothetical cannabis consumption in grams from legal ("from a dispensary") and illegal ("from a dealer") sources, separately, at 20 escalating prices: free, $\$ 1, \$ 2, \$ 4, \$ 6, \$ 8, \$ 10, \$ 12, \$ 14$, $\$ 16, \$ 18, \$ 20, \$ 25, \$ 30, \$ 35, \$ 40, \$ 45, \$ 50, \$ 55$, and $\$ 60$ per gram. Two substitution MPTs measured hypothetical consumption of concurrently available legal and illegal cannabis, with the one option at the same adjusting prices (free- $\$ 60 / \mathrm{g}$ ) and the alternative at a fixed price $(\$ 10 / \mathrm{g})$. Participants completed two substitution MPTs, in a counterbalanced order: (1) an adjusting legal price/fixed illegal price version and (2) a fixed legal price/ adjusting illegal price version. Although the price of legal cannabis in Canada was not released at the time of data collection, $\$ 10 / \mathrm{g}$ was chosen based on statements by federal and Ontario policymakers suggesting that this price was being actively considered (Campion-Smith 2017; Crawley 2017). Participants were provided with an instructional vignette describing the MPT and the specific parameters of the two sources (complete vignettes provided in Supplementary Material). 


\section{Demand for Legalized and Illegal Cannabis Available Alone}

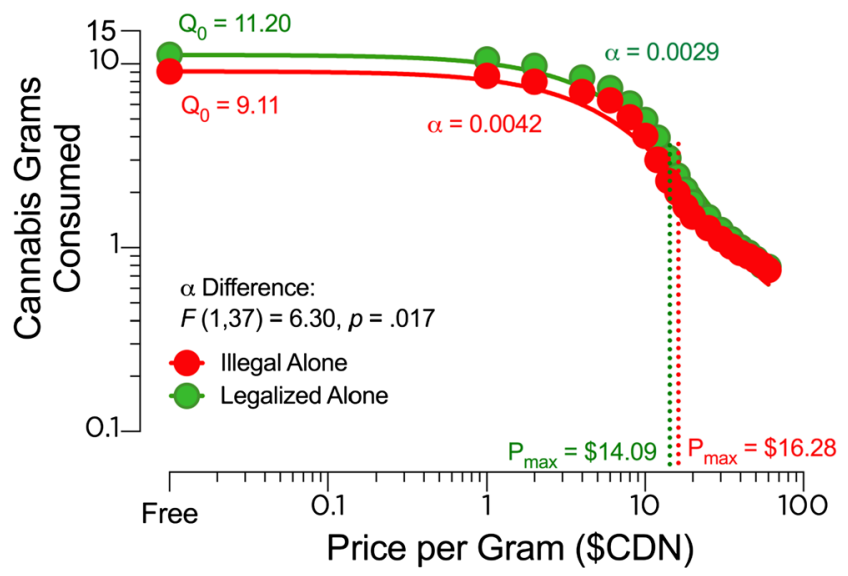

Fig. 1 Demand for legalized and illegal cannabis available alone

Mean consumption values at each price were analyzed using established demand curve modeling techniques (Aston et al. 2015; Hursh 2014). Consumption values are plotted as a function of price per gram to yield a demand curve which is used to generate several demand indices, including elasticity $(\alpha)$, the price at which demand became elastic $\left(P_{\max }\right)$, and consumption at free price $\left(Q_{0}\right.$, or intensity of demand). Substitution was quantified via two indices: (1) cross-price elasticity calculated as the linear slope of the consumption curve of the fixedprice alternative, with a significant positive slope indicating substitution (Johnson et al. 2017); and (2) an exponential cross-price elasticity model, with a negative value for the I parameter indicating substitution (Hursh 2014).

\section{Results}

Consumption on the MPTs revealed prototypical demand curves (Fig. 1). The relative value of legal cannabis from a dispensary was greater than the illegal option, as reflected by greater $Q_{0}\left(\sim 2 \mathrm{~g}\right.$ difference at free price), higher $P_{\max }$ price ( $\sim 2$ difference), and lower elasticity for the legal option $(F(1,37)=6.3, p=0.017)$.

Substitution curves are presented in Fig. 2 and index-level data are in Table 1 (price-level data provided in Table S1-S2 in Supplementary Materials). Substitution was confirmed by negative $I$ values for both fixed-priced alternatives (illegal = -0.67 ; legal $=-0.43)$, and these values were significantly different $(F(1,34)=17.25, p=0.0002)$. Both alternatives also had significant positive linear cross-price elasticities (illegal = 0.20 ; legal $=0.13 ; p<0.001)$. The availability of the legal cannabis alternative had a substantially greater effect on the elasticity of illegal cannabis $(\Delta \alpha=0.0053 ; F(1,37)=82$, $p<0.0001)$ than the opposite situation $(\Delta \alpha=0.0017$; $F(1,37)=42, p<0.0001)$, a threefold difference. This was also evident for $P_{\max }\left(\Delta P_{\text {max }}\right.$ : illegal $=\$ 8.05$, legal $\left.=\$ 4.44\right)$.

Sensitivity analyses revealed that the pattern of results (e.g., asymmetric substitution for legal over illegal cannabis) was essentially identical in men vs. women, older vs. younger participants, and high vs. low income (see Table 1). In the case of cannabis involvement, hazardous users (high-CUDIT) tended to be less sensitive to the presence of the legal alternative compared to nonhazardous users. Although both groups exhibited asymmetric substitution, the magnitude of the asymmetry in the low-CUDIT group ( $\Delta \alpha=0.0150$ vs. 0.0042$)$ was nearly twice as large as the high-CUDIT group $(\Delta \alpha=$ 0.0031 vs. 0.0016$)$.

\section{Effect of Legal Cannabis Availability on Illegal Cannabis Consumption}
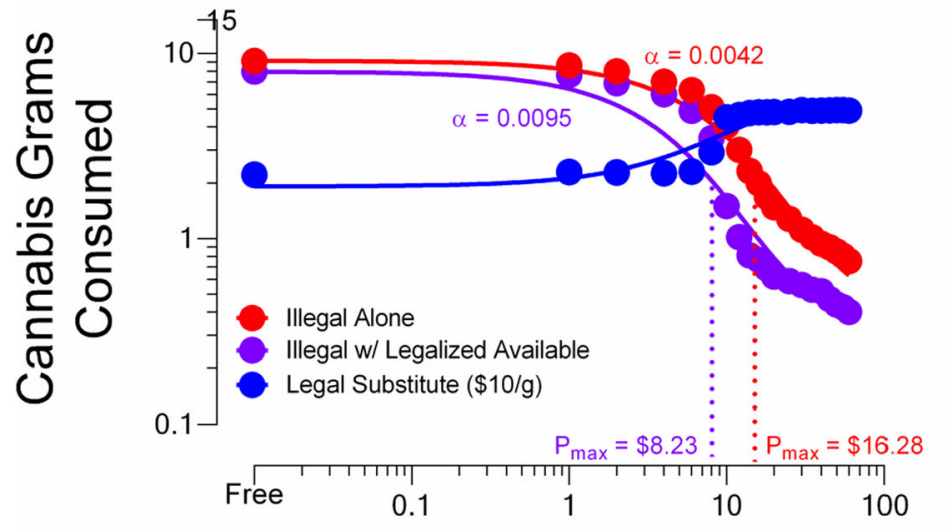

\section{Pric}

Fig. 2 Effect of cannabis availability on cannabis consumption

\section{Effect of Illegal Cannabis Availability on Legal Cannabis Consumption}

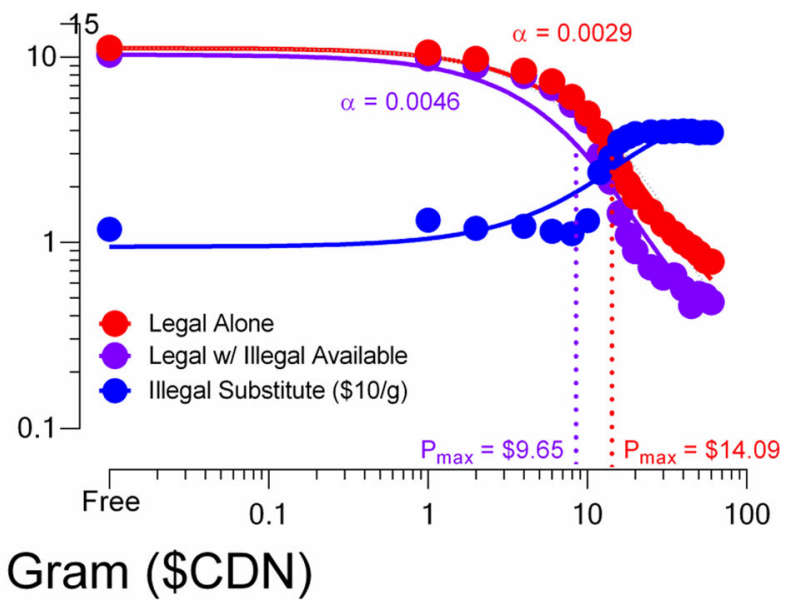


Table 1 Overall results and sensitivity analyses examining patterns of substitutability between legal and illegal cannabis by age, income, sex, and cannabis use severity

\begin{tabular}{|c|c|c|c|c|c|c|c|c|c|c|}
\hline \multirow[t]{2}{*}{ Group } & \multirow[t]{2}{*}{ Source } & \multicolumn{3}{|l|}{ Alone } & \multicolumn{3}{|c|}{ Alternative available } & \multicolumn{3}{|c|}{ Elasticity comparison } \\
\hline & & $Q_{0}$ & $P_{\max }$ & Elasticity $(\alpha)$ & $Q_{0}$ & $P_{\max }$ & Elasticity $(\alpha)$ & $\Delta \alpha$ & $F$ & $p$ \\
\hline \multirow[t]{2}{*}{ Total Sample } & Illegal & 9.12 & 16.26 & 0.0042 & 7.97 & 8.22 & 0.0095 & 0.0053 & 82.0 & $<0.0001$ \\
\hline & Legal & 11.20 & 14.09 & 0.0029 & 10.31 & 9.65 & 0.0046 & 0.0017 & 42.0 & $<0.0001$ \\
\hline \multirow[t]{2}{*}{ Age $<32$} & Illegal & 9.32 & 13.64 & 0.0036 & 8.68 & 6.51 & 0.0081 & 0.0039 & 94.0. & $<0.0001$ \\
\hline & Legal & 11.48 & 11.86 & 0.0030 & 10.72 & 8.28 & 0.0046 & 0.0016 & 25.0 & $<0.0001$ \\
\hline \multirow[t]{2}{*}{ Age $\geq 32$} & Illegal & 8.86 & 14.80 & 0.0049 & 7.19 & 8.12 & 0.0110 & 0.0061 & 65.0 & $<0.0001$ \\
\hline & Legal & 14.44 & 12.85 & 0.0022 & 9.82 & 12.60 & 0.0033 & 0.0011 & 50.0 & $<0.0001$ \\
\hline Income & Illegal & 9.31 & 21.22 & 0.0042 & 7.71 & 11.33 & 0.0095 & 0.0053 & 66.0 & $<0.0001$ \\
\hline$<\$ 79,000$ & Legal & 11.27 & 14.52 & 0.0032 & 10.60 & 9.69 & 0.0051 & 0.0019 & 30.0 & $<0.0001$ \\
\hline Income & Illegal & 8.85 & 14.09 & 0.0042 & 8.30 & 6.57 & 0.0096 & 0.0054 & 99.0 & $<0.0001$ \\
\hline$\geq \$ 79,000$ & Legal & 11.10 & 15.33 & 0.0024 & 9.92 & 10.29 & 0.0040 & 0.0016 & 60.0 & $<0.0001$ \\
\hline \multirow[t]{2}{*}{ Male } & Illegal & 10.89 & 16.86 & 0.0035 & 9.62 & 8.05 & 0.0083 & 0.0048 & 98.0 & $<0.0001$ \\
\hline & Legal & 13.05 & 17.45 & 0.0023 & 11.80 & 11.38 & 0.0039 & 0.0016 & 56.0 & $<0.0001$ \\
\hline \multirow[t]{2}{*}{ Female } & Illegal & 6.64 & 8.80 & 0.0032 & 5.50 & 3.95 & 0.0086 & 0.0054 & 130.0 & $<0.0001$ \\
\hline & Legal & 8.44 & 8.60 & 0.0040 & 8.08 & 6.42 & 0.0056 & 0.0016 & 79.0 & $<0.0001$ \\
\hline \multirow[t]{2}{*}{ CUDIT $<8$} & Illegal & 5.86 & 7.80 & 0.0074 & 4.88 & 4.62 & 0.0150 & 0.0076 & 52.0 & $<0.0001$ \\
\hline & Legal & 8.13 & 8.95 & 0.0033 & 7.67 & 7.45 & 0.0042 & 0.0009 & 29.0 & $<0.0001$ \\
\hline \multirow[t]{2}{*}{ CUDIT $\geq 8$} & Illegal & 13.63 & 9.95 & 0.0020 & 12.49 & 7.01 & 0.0031 & 0.0011 & 128.0 & $<0.0001$ \\
\hline & Legal & 17.24 & 11.36 & 0.0013 & 16.54 & 9.62 & 0.0016 & 0.0003 & 51.0 & $<0.0001$ \\
\hline Group & Source & Slope & $p$ & $F$ & $p$ & $I$ & $F$ & $p$ & & \\
\hline \multirow[t]{2}{*}{ Total sample } & Illegal substitute & 0.20 & 0.0004 & 1.66 & 0.207 & -0.67 & 17.30 & $<0.001$ & & \\
\hline & Legal substitute & 0.13 & $<0.0001$ & & & -0.43 & & & & \\
\hline \multirow[t]{2}{*}{ Age $<32$} & Illegal substitute & 0.21 & 0.0005 & 1.02 & 0.319 & -0.71 & 6.21 & 0.018 & & \\
\hline & Legal substitute & 0.15 & $<0.0001$ & & & -0.48 & & & & \\
\hline \multirow[t]{2}{*}{ Age $\geq 32$} & Illegal substitute & 0.19 & 0.0003 & 2.60 & 0.116 & -0.65 & 16.07 & $<0.001$ & & \\
\hline & Legal substitute & 0.12 & $<0.0001$ & & & -0.37 & & & & \\
\hline Income & Illegal substitute & 0.18 & 0.0002 & 0.63 & 0.431 & -0.59 & 3.38 & 0.075 & & \\
\hline$<\$ 45,000$ & Legal substitute & 0.15 & $<0.0001$ & & & -0.45 & & & & \\
\hline Income & Illegal substitute & 0.23 & 0.0009 & 3.00 & 0.092 & -0.81 & 10.03 & 0.003 & & \\
\hline$\geq \$ 45,000$ & Legal substitute & 0.12 & 0.0002 & & & -0.39 & & & & \\
\hline \multirow[t]{2}{*}{ Male } & Illegal substitute & 0.18 & 0.0004 & 1.17 & 0.287 & -0.62 & 7.09 & 0.012 & & \\
\hline & Legal substitute & 0.13 & $<0.0001$ & & & -0.42 & & & & \\
\hline \multirow[t]{2}{*}{ Female } & Illegal substitute & 0.29 & 0.0006 & 3.60 & 0.066 & -0.98 & 10.21 & 0.003 & & \\
\hline & Legal substitute & 0.14 & 0.0004 & & & -0.47 & & & & \\
\hline \multirow[t]{2}{*}{ CUDIT $<8$} & Illegal substitute & 0.29 & 0.0009 & 1.76 & 0.193 & -1.02 & 6.84 & 0.013 & & \\
\hline & Legal substitute & 0.18 & 0.0003 & & & -0.60 & & & & \\
\hline \multirow[t]{2}{*}{ CUDIT $\geq 8$} & Illegal substitute & 0.17 & 0.0004 & 3.55 & 0.075 & -0.58 & 21.3 & $<0.0001$ & & \\
\hline & Legal substitute & 0.90 & $<0.0001$ & & & -0.22 & & & & \\
\hline
\end{tabular}

Age and income groups based on a median split; CUDIT, Cannabis Use Disorders Identification Test, grouping based on recommended cutoff score for hazardous use of 8 or higher

\section{Summary and implications}

Using a behavioural economic substitution framework, we report empirical evidence that cannabis users treat regulated cannabis to be a superior commodity to illegal cannabis.
Moreover, we found evidence of asymmetrical substitutability, such that the presence of legal cannabis substantially decreased demand for illegal cannabis, but the reverse effect was significantly smaller. Specifically, the availability of the legal option increased elasticity of illegal cannabis by $126 \%$, 
whereas the presence of the illegal substitute increased elasticity of legal cannabis by $59 \%$. These results suggest that the introduction of legal cannabis into the market may disrupt and reduce illegal purchases, but specific pricing will determine the extent of this disruption. When priced the same or slightly higher (i.e., $\$ 10-\$ 12 / g$ ), the legal cannabis was clearly preferred and suppressed illegal purchasing, but above these prices, preferences switched to the illegal option (see Table S1).

There are several potential reasons for the observed preference for legal cannabis. These include the perception of higher quality control standards, known cannabinoid/THC levels, and no risk of legal consequences with the legal option. These were directly specified in the experimental task and were part of the rationale for Bill C-45. Future studies using qualitative approaches may reveal specific reasons behind the asymmetric preference for legal cannabis. More broadly, these findings converge with previous studies using substitutability analysis to inform public policy, e.g., Johnson et al. (2017), including a parallel study from US states with legalized recreational cannabis (Amlung et al. 2018).

Several considerations pertain to these findings. First, data were collected via an online platform which has reduced experimental control relative to in-person assessment. Second, the MPTs were hypothetical, and since recreational cannabis was still illegal at the time of data collection, choices were based on a simulated legal market. Studies with other addictive commodities (e.g., alcohol, tobacco) have revealed a close correspondence between hypothetical and actual outcomes (Amlung et al. 2012; Amlung and MacKillop 2015); however, this has not been demonstrated for cannabis. It is notable that the effects observed were generally large in magnitude, suggesting the general preference topography is likely valid. A third important consideration is use of "dispensary" for the legal source since many illegal storefronts in Ontario refer to themselves as dispensaries. This term may have unintended connotations that were not consistent with the instructional vignettes, and findings may have been different if another term was used (e.g., legal storefront). Fourth, the substitution paradigm only assessed a single fixed price for the alternative $(\$ 10 / \mathrm{g})$, and a priority for future research is to assess substitutability using actual prices of legal cannabis. Finally, although the levels of cannabis use were comparable to general cannabis users in Ontario (Ialomiteanu et al. 2016), these findings may not generalize to other Canadian provinces or territories.

Acknowledging these points, these data nonetheless represent a rare direct examination of the substitutability of legal and illegal cannabis. The results provide initial empirical evidence that legal cannabis is a preferred and asymmetrically substitutable commodity, but also reveal that this preference is far from inviolable. Pricing policy will need to be optimized to maximize the benefits of a legally regulated cannabis marketplace.

Funding This research was funded, in part, by the Michael G. DeGroote Centre for Medicinal Cannabis Research at McMaster University and the Peter Boris Centre for Addictions Research at McMaster University/St. Joseph's Healthcare Hamilton. Funders had no role in the research or the decision to publish. JM is a principal in BEAM Diagnostics, Inc.

\section{Compliance with ethical standards}

All participants gave informed consent and received gift cards as incentives; the study was approved by the Hamilton Integrated Research Ethics Board.

Conflict of interest The authors declare that they have no conflicts of interest.

Publisher's Note Springer Nature remains neutral with regard to jurisdictional claims in published maps and institutional affiliations.

\section{References}

Amlung, M., \& MacKillop, J. (2015). Further evidence of close correspondence for alcohol demand decision making for hypothetical and incentivized rewards. Behav Process, 113, 187-191. https://doi.org/ 10.1016/j.beproc.2015.02.012.

Amlung, M., Acker, J., Stojek, M. K., Murphy, J. G., \& MacKillop, J. (2012). Is talk "cheap"? An initial investigation of the equivalence of alcohol purchase task performance for hypothetical and actual rewards. Alcohol Clin Exp Res, 36(4), 716-724. https://doi.org/10. 1111/j.1530-0277.2011.01656.x.

Amlung, M., Reed, D. D., Morris, V., Aston, E. R., Metrik, J., \& MacKillop, J. (2018). Price elasticity of illegal versus legal cannabis: a behavioral economic substitutability analysis. Addiction. https:// doi.org/10.1111/add.14437.

Aston, E. R., Metrik, J., \& MacKillop, J. (2015). Further validation of a marijuana purchase task. Drug Alcohol Depend, 152, 32-38. https:// doi.org/10.1016/j.drugalcdep.2015.04.025.

Campion-Smith, B. (2017). Legalized pot to cost $\$ 10$ a gram, finance ministers say. The Toronto Star. https://www.thestar.com/news/ canada/2017/12/11/legalized-pot-to-cost-10-a-gram-financeministers-say.html. Published December 11. Accessed 17 October 2017

Canadian Centre on Substance Abuse. Cannabis. Ottawa, ON. 2017.

Collins, R. L., Vincent, P. C., Yu, J., Liu, L., \& Epstein, L. H. (2014). A behavioral economic approach to assessing demand for marijuana. Exp Clin Psychopharmacol, 22(3), 211-221. https://doi.org/10. 1037/a0035318.

Crawley, M. (2017). Ontario considers pricing recreational pot at $\$ 10$ a gram. CBC News. http://www.cbc.ca/news/canada/toronto/ marijuana-price-ontario-10-gram-1.4298540. Published September 20. Accessed 17 Oct 2017.

Hursh, S. R. (2014). Behavioral economics and the analysis of consumption and choice. In: McSweeney, F. K., Murphy, E. S. eds. The Wiley Blackwell handbook of operant and classical conditioning. Hoboken 275-305.

Ialomiteanu, A. R., Hamilton, H. A., Adlaf, E. M., Mann, R. E. (2016). CAMH Monitor eReport 2015: substance use, mental health and 
well-being among Ontario adults 1977-2015 (CAMH Research Document Series No. 45). Toronto, ON.

Johnson, M. W., Johnson, P. S., Rass, O., \& Pacek, L. R. (2017). Behavioral economic substitutability of e-cigarettes, tobacco cigarettes, and nicotine gum. J Psychopharmacol, 31(7), 851-860. https://doi.org/10.1177/0269881117711921.
Rehm, J., Crépault, J.-F., \& Fischer, B. (2016). The devil is in the details! On regulating cannabis use in Canada based on public health criteria. Int J Heal Policy Manag Heal policy Manag, 6(3), 173176. https://doi.org/10.15171/ijhpm.2016.114.

Volkow, N. D., Baler, R. D., Compton, W. M., \& Weiss, S. R. B. (2014). Adverse health effects of marijuana use. $N$ Engl J Med, 370(23), 2219-2227. https://doi.org/10.1056/NEJMra1402309. 